\title{
No Fragmentation
}

\author{
Jon Kabat-Zinn ${ }^{1}$
}

Published online: 15 March 2018

(C) Jon Kabat-Zinn 2018

As you may have experienced by now to some degree just in paying a bit more careful attention to the activity of your own mind and body from moment to moment, we tend to lead rather fragmented lives, both inwardly and outwardly. And we contribute to and participate in this fragmentation through a temporary forgetting of who we actually are in our deepest nature, and by our impulse to be, not as we are, but as others, or even our own fantasizing would have us be. Thus, we split ourselves off from ourselves. We fragment ourselves to pursue chimera, often for years and decades at a stretch, and in the process, lose touch with or even betray at times our true nature, our sovereignty, the beauty of who we actually are, and our unfragmented, unfragmentable wholeness. This is one symptom of our endemic distress and dis-ease, as individuals and as a society. Perhaps this splitting ourselves off from ourselves is the root conflict. Perhaps it lies at the core of all conflict.

Healing is a process; one that involves the recognition of our wholeness, and a steadfast refusal to allow ourselves to be fragmented, even when we are terrified, or broken apart by life. Ultimately, healing is a coming to terms with things as they are, rather than struggling to force them to be as they once were, or as we would like them to be to feel secure, or to have what we sometimes think of as our own way. As Saki

Excerpted from the book Coming To Our Senses: Healing Ourselves and the World Through Mindfulness by Jon Kabat-Zinn. Copyright (C) 2005 Jon Kabat-Zinn, Ph.D. Published by Hachette Books. All Rights Reserved.

Jon Kabat-Zinn

mindfulness@umassmed.edu

1 Center for Mindfulness, University of Massachusetts Medical School, 55 Lake Avenue North, Worcester, MA 01655, USA
Santorelli put it in his book Heal Thy Self: Lessons on Mindfulness in Medicine, healing is a matter of knowing that we can be shattered and yet we are still whole.

Emily Dickinson captures so utterly poignantly this endemic impulse to split off parts of ourselves, to fragment in the face of our own fear, and wounds:

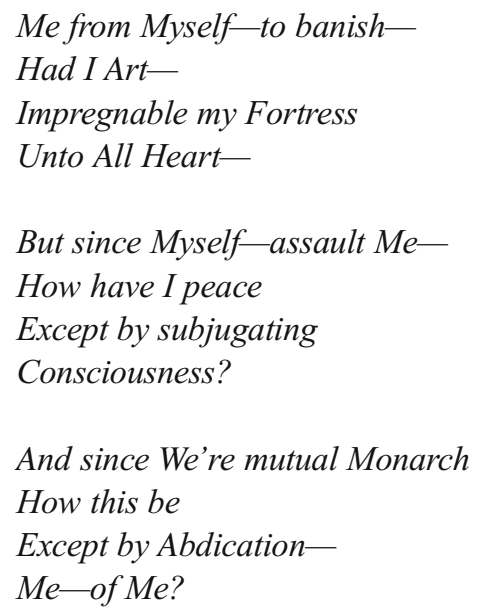

How often do we voluntarily but unwittingly banish ourselves from ourselves, abdicate our wholeness, and subjugate our consciousness, our sentience and our common sense, our very sovereignty and the possibilities of true healing, in the hope of achieving invulnerability, to protect ourselves from more hurt, to lessen our pain?

What is the price we pay for such abdication? Is it worth it?

What if we were to choose, bravely, not to subjugate our consciousness any longer? Or even in just one moment?

Who would we be?

How might we feel, inwardly?

How might we act, outwardly? 